\title{
Compaction of Confining Materials in Pillar Blast Tests
}

\author{
N. Petropoulos ${ }^{1}$ (D) M. Wimmer ${ }^{2} \cdot$ D. Johansson ${ }^{1} \cdot$ E. Nordlund ${ }^{1}$
}

Received: 18 October 2017 / Accepted: 28 February 2018 / Published online: 6 March 2018

(c) The Author(s) 2018. This article is an open access publication

\begin{abstract}
Two confined pillar tests were conducted at the Kiirunavaara mine to investigate the degree of compaction of three materials, i.e., 0-32-mm backfilled material, a blend of ore and waste material and caved material. Two blastholes were drilled parallel to each pillar wall, and several measurement holes were drilled in between the blastholes through each pillar. Both the measurement holes and backfilled materials, except the caved material, were instrumented. Two types of measurements were taken: dynamic measurements with accelerometers, and static measurements which considered the location of the instrumentation pre- and post-blast. Dynamic measurements involved the burden movement and the confining material behavior, and static measurements contained the final location of sensors inside and the angle of repose of the confining material. The results showed that the size distribution of the confining material affects its behavior under dynamic loading. The backfilled materials showed an apparent cohesion forming an agglomeration on the surface of the blasted burden. The burden moved as one slab due to simultaneous detonation. A gap was formed between the blasted burden and the new face. This gap was partially filled with burden erosion material which was finer fragmented than the blasted burden material.
\end{abstract}

Keywords Compaction $\cdot$ Burden movement $\cdot$ Pillar tests $\cdot$ Sublevel caving $\cdot$ Confined blasting

\section{Introduction}

Sublevel caving (SLC) is a mass mining method used at the Kiirunavaara mine owned and operated by LKAB (Luossavaara-Kiirunavaara Aktiebolag) in northern Sweden (Fig. 1). With increasing scale, it has become one of the most efficient underground bulk mining methods for inclined orebodies. The major drawbacks of SLC are ore losses the waste rock dilution (Bull and Page 2000). The method has three core elements; i) drilling, ii) blasting and iii) flow of

N. Petropoulos

nikolaos.petropoulos@1tu.se

M. Wimmer

matthias.wimmer@1kab.com

D. Johansson

Daniel.Johansson@1tu.se

E. Nordlund

Erling.Nordlund@1tu.se

1 Division of Mining and Geotechnical Engineering, Department of Civil, Environmental and Natural Resources Engineering, Luleå University of Technology, Luleå, Sweden

2 LKAB, Kiruna, Sweden the blasted material (Wimmer 2012). The production blast is performed in sub-vertical blastholes drilled in fan-shaped pattern referred to as SLC production rings. The blast is done under confined conditions, which means that there is material in front of the burden to be blasted (either ore and/ or waste rock). The result of the confined blast is highly influenced by the interaction between the blasted material and the caved material. Both materials change their characteristics during blasting; the blasted material increases its porosity and compressibility due to breakage and swelling. On the other hand, the caved material is compacted and decreases in porosity and compressibility.

The behavior of the blasted material under confined conditions has been studied by several researchers in different experimental configurations. Several types of confining materials have been used to study the interaction between the blasted and confining material.

Belen'kii et al. (1969) conducted a series of smallscale tests to investigate the compaction of confining material. The models were made from sheet iron with $10 \mathrm{~mm}$ wall thickness. The dimensions of the models were $400 \times 400 \times 500 \mathrm{~mm}$, and the confining material was crushed martite and hydrohematite-martite ore with predefined particle size distribution. The results showed that 


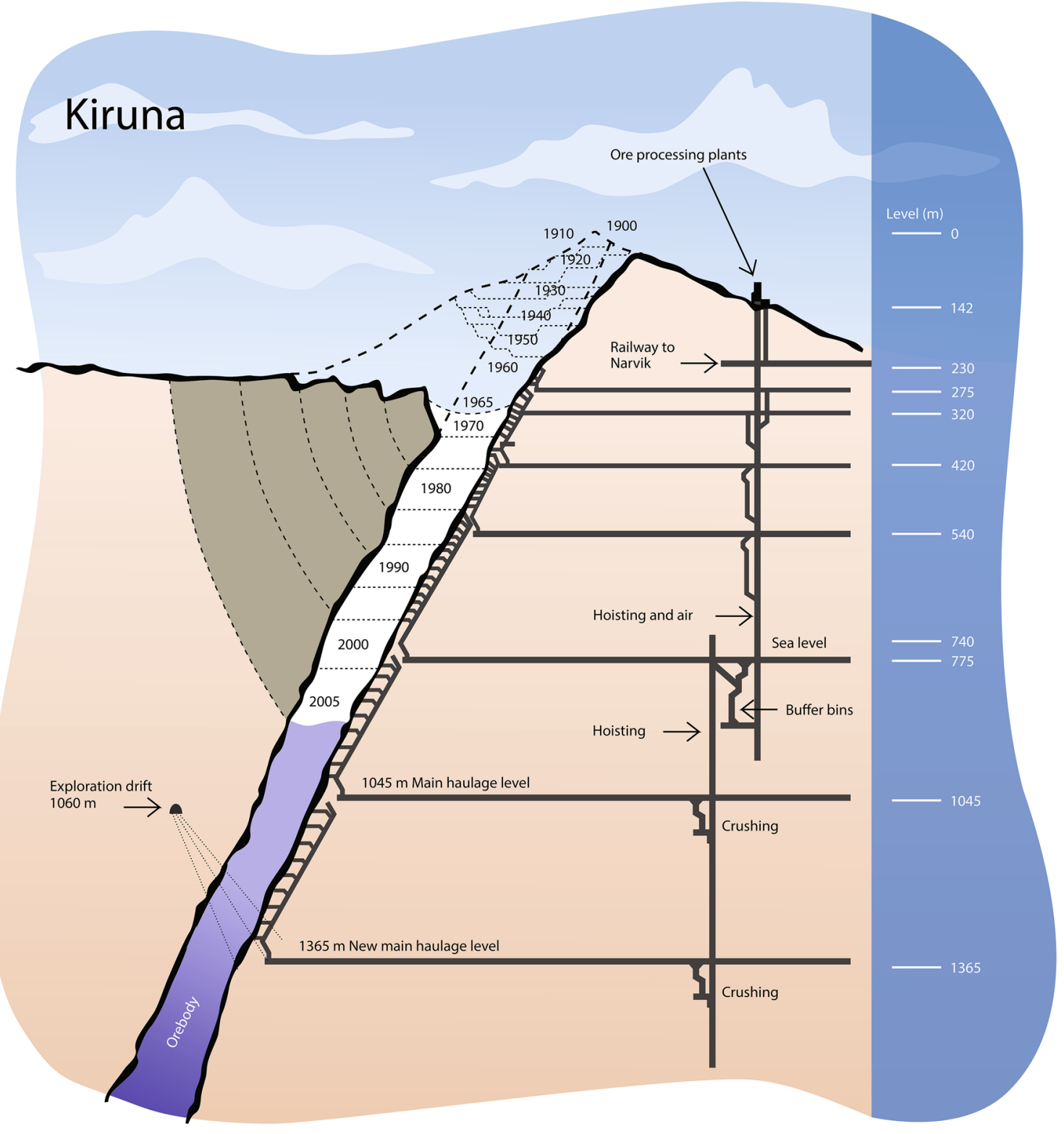

Fig. 1 Kiirunavaara mine, image courtesy of LKAB

the compaction only depends on the confined layer thickness of the crushed martite. A general conclusion based on all the tests was that compaction could be expressed with a hyperbolic function.

Rustan $(1970,2013)$ investigated the burden movement during blasting. The setup was composed of a SLC-silo profile model (in scale 1:50 with respect to an SLC production ring) which was made of magnetite mortar and was confined with crushed limestone. High-speed filming was utilized to measure the burden velocity. The maximum recorded velocity reached $24 \mathrm{~m} / \mathrm{s}$.

Volchenko (1977) investigated the impact of the blasthole location and delay time on fragmentation of the blasted material by conducting small-scale confined blasting tests. The specimens were cuboid iron ore pieces with two dimensions, namely $120 \times 100 \times 200$ and $300 \times 275 \times 245 \mathrm{~mm}$. The confining material consisted of a variety of crushed materials. The results showed that the fragmentation was influenced by the confining material, blasting scheme and delay time. It was also found that the swell of the blasted material decreased and the extent of the compaction zone of the confining material increased which led to a higher bulk density of the confining material when the thickness of the confining material increased. The largest swell/compaction was observed in row-by-row blasting and spacing-to-burden $(\mathrm{S} / \mathrm{B})$ ratio of 1.78 . These findings were applied to industrial 
scale tests, resulting in a good agreement with the results from the small-scale tests.

Johansson (2011) conducted a series of small-scale tests with cylindrical $(\varnothing 140 \times 280 \mathrm{~mm})$ and cuboid $(660 \times 205 \times 210 \mathrm{~mm})$ models placed in a concrete yoke to study the influence of confinement and delay time on fragmentation and rock compaction. The models were made of magnetic mortar. Different types of confining material were tested, namely crushed granite and crushed concrete. The fragmentation of the confining material was scaled to 1:30 of SLC blasted material. The results showed that the compaction is significantly affected by the specific charge used in the specimens and the properties of the confining material. A prediction model was proposed to estimate the compaction of granular materials with respect to the specific charge and the acoustic impedance.

Petropoulos et al. (2013) studied the burden behavior under confined conditions with an experimental setup based on earlier work done by Johansson (2011). The confining material was crushed concrete. The blocks were instrumented with custom-made incremental displacement sensor. The average maximum burden velocity and burden displacement were $29 \mathrm{~m} / \mathrm{s}$ and $12.6 \mathrm{~mm}$ (S/B was 1.41 ), respectively. It was also observed that the burden moved a few millimeters backward after reaching its maximum displacement but the used instrumentation could not capture this behavior.

The above-mentioned experimental work has been performed under controlled conditions in terms of blasted material and the confining material properties. The findings from the small-scale tests need to be verified in large-scale tests. However, as the scale of the test increases, the complexity of the tests also increases since more uncertainties are involved which cannot be controlled, for example, geology and borehole deviation.

Newman (1996) performed a pillar test in the Kiirunavaara mine. The scope of the tests was to study the ore swell and to estimate the amount of blast damage in an SLC production ring blast. The experimental design was to blast a wall of an ore pillar confined by the caved material. Three blastholes were drilled parallel to the wall of the drift with a burden of $3 \mathrm{~m}$. The orientation of the blastholes was similar to an SLC ring, i.e., fan-shaped. Drill cores were extracted from the neighboring drift into the burden pre- and postblast. The results showed a variation of the swell from 2 to $17 \%$. One suggested explanation for this variation was that the caved material had inconsistent degree of packing, i.e., varying bulk density. The properties of the caved material were not analyzed in detail.

Wimmer and Ouchterlony (2011) carried out a series of pillar tests to develop measurement methods for the study of burden dynamics and breakage. Two out of these tests were in a configuration similar to the confined conditions as in the SLC method. The drift in front of the burden in those tests was backfilled with material from drift development, i.e., a blend of ore and waste rock. The results showed that the burden moved about 1.2-1.6 m, and the compaction was in the range of $4-5 \%$. However, the material properties have not been analyzed in detail. This makes it complex to draw any qualitative conclusions on the influence of the blast on the caved material.

The present paper describes the results from two recent pillar tests. The aim of these pillar tests was to develop instrumentation, installation techniques and to observe the reaction of backfilled and caved material during blasting as well as the burden behavior. Similar conditions can be found in production SLC rings where the blast is performed under confined conditions.

\section{Experimental Design}

Two pillar tests were conducted under confined conditions in the Kiirunavaara mine. The location of the test site was at production block 45 , at $935 \mathrm{~m}$ below the surface $(935 \mathrm{~m}$ level). The dominant rock type in both pillar tests was trachyte-trachyandesite. The rock mass in this area was competent with 4 major joint sets with strike/dip $246^{\circ} / 60^{\circ}, 63^{\circ} / 60^{\circ}$, $60^{\circ} / 60^{\circ}$ and $56^{\circ} / 60^{\circ}$, respectively. The first pillar test was mainly focused on the evaluation of the new installation techniques and the instrumentation. The new techniques included, for example, anchoring of the measurement systems, stemming and initiation of the explosives. The second pillar test was aimed to measure the burden movement and the confining material response to the burden movement. Hereafter, the two pillar tests will be named test \#1 for pillar $\# 1$ and test \#2 for pillar \#2.

The conceptual design of the pillar tests is shown in Fig. 2. The measurement systems were installed from the rear side of the measurement hole toward the burden. The reason for this installation was that there was limited access to the front side of the pillars due to the backfilled or caved materials, especially in test \#2. The measurement systems were installed $0.2 \mathrm{~m}$ from the face of the burden behind the shotcrete support layer. The hole diameter was $\varnothing 115 \mathrm{~mm}$ for both the blastholes and the measurement holes. The blastholes were drilled parallel to the drift wall to simulate the two middle holes of a production SLC ring. Then, similar conditions were applied, i.e., simultaneous initiation of the blastholes and similar specific charge, especially in test \#2. The average specific charge of an SLC production ring at the Kiirunavaara mine is $1.35 \mathrm{~kg} / \mathrm{m}^{3}$ according to Wimmer (2012) where in test \#2, the specific charge was $1.48 \mathrm{~kg} / \mathrm{m}^{3}$.

Table 1 shows the blast design of the pillar tests. The ratio between the burden and the spacing was changed, from 1.25 in test \#1 to 1.0 in test \#2, to compensate for irregularities 
Fig. 2 Conceptual design of the pillar tests (DAS: data acquisition system) (section view of the pillar)

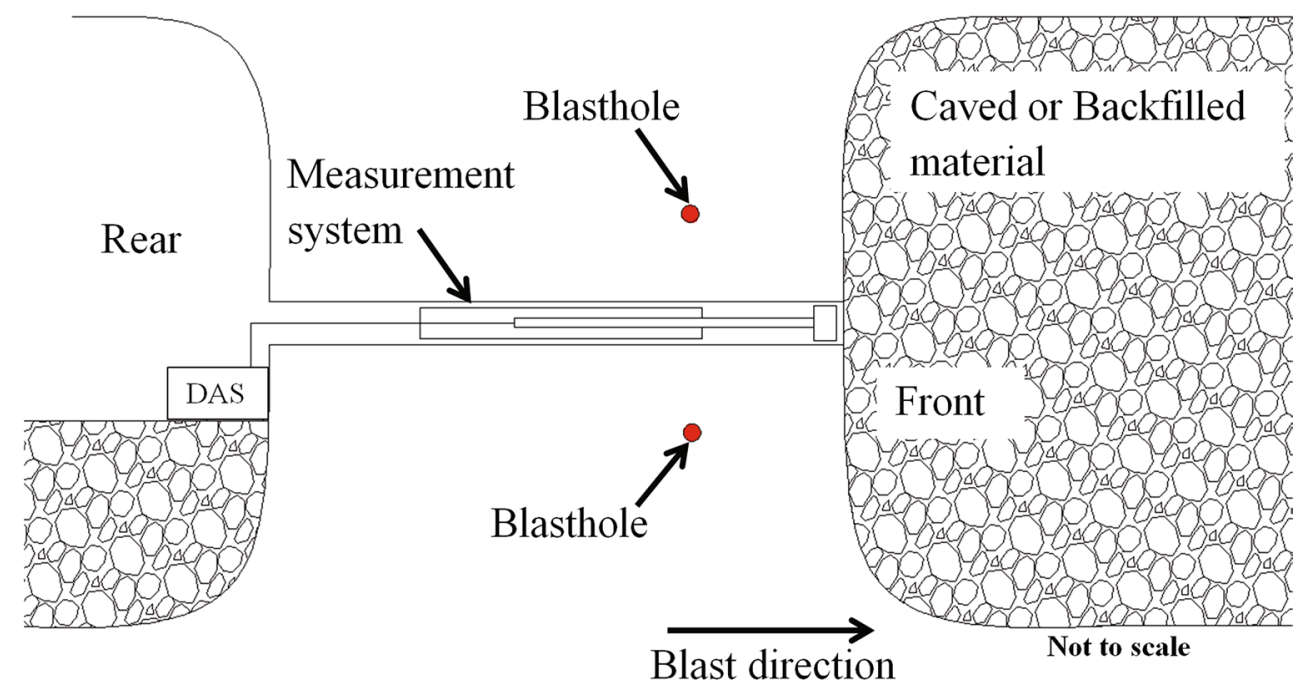

Table 1 Geometry of the pillar tests

\begin{tabular}{lllcll}
\hline $\begin{array}{l}\text { Pillar } \\
\text { tests }\end{array}$ & $\begin{array}{l}\text { Burden } \\
(\mathrm{m})\end{array}$ & $\begin{array}{l}\text { Spacing } \\
(\mathrm{m})\end{array}$ & $\begin{array}{l}\text { Blasthole } \\
\text { length } \\
(\mathrm{m})\end{array}$ & $\begin{array}{l}\text { Stem- } \\
\text { ming }(\mathrm{m})\end{array}$ & $\begin{array}{l}\text { Specific } \\
\text { charge }(\mathrm{kg} / \\
\left.\mathrm{m}^{3}\right)\end{array}$ \\
\hline Test \#1 & 2.5 & 2.0 & 9.5 & 3.0 & 1.07 \\
Test \#2 & 2.0 & 2.0 & 45.0 & 5.0 & 1.48 \\
\hline
\end{tabular}

of the pillar wall and to ensure sufficient energy to push the burden toward the backfilled/caved material and compact it.

The final setup of the pillar tests is shown in Fig. 3. The cross-sectional area of the drifts was $5 \times 7 \mathrm{~m}$, with some variations due to irregular walls and roof. The pillar width was $17 \mathrm{~m}$ which was also the length of the measurement holes.

In test \#1, two measurement holes (M11 and M12) and two blastholes were drilled. The backfilled material in test \#1 was a blend of ore and waste rock from drift development with unknown particle size distribution and characteristics since the test was mainly focused on evaluating the instrumentation and the installation techniques. Timber markers were placed inside the backfilled material in drift 436 at 2 and $4 \mathrm{~m}$ distance from the burden toward the opposite wall.

In test \#2, the pillar was divided into two parts, i.e., the backfilled part and the caved mass region where drift 433 was filled with caved masses from production blasts. The caved mass region started from the floor line of the muckpile (Fig. 3). Two sets of holes were used to investigate the behavior of the burden, namely one set of holes toward backfilled material and one set of holes toward caved masses. Totally, 11 holes were drilled for test \#2 and different types of instrumentation were installed. TDR cables (time-domain reflectometry) were installed in 3 holes (noted in Fig. 3 as TDR\#), measurement systems were installed (noted in the figure as $\mathrm{M \# )}$ in 6 holes, and 2 holes were used for inspection (noted in Fig. 3 as Insp). The majority of the holes in test \#2 were drilled through the pillar to monitor the behavior of the caved material. The backfilled material was a coarse-grained crushed aggregate as characterized by ASTM D2487-11 (2011) in a pendular state with a maximum particle size of $32 \mathrm{~mm}$. The backfilling material was studied in laboratory conditions by Petropoulos et al. (2017) and had a finer particle size than the caved material. The backfilled material was also instrumented (M7-M10) to monitor the behavior of it during blasting.

In both pillar tests, the drift area was calculated based on scan data before the blast to consider the irregularities of the wall and the roof. The backfilled material was removed to measure the post-blast location of the timber markers and instrumentation in the material. The location of the markers was defined by means of a total station pre- and post-blast. After these measurements, the change in the occupied area of the drift in a 2-D plane was calculated. Then, the volumetric change (compaction) was correlated with that area.

After the blast, the new face of the intact rock was captured with geo-referenced 3D imaging technique (3GSM 2010). The reason for this measurement was to identify the shape of the new face of the pillar after the blast.

\subsection{Instrumentation and Installation Techniques}

The design was inspired by earlier work done by Wimmer (2012). The measurement system installed in the burden had a telescopic design where the anchor and the pulling tube were moving while the protective pipe was stationary and anchored in the rock (Petropoulos et al. 2015). The main parts of the measurement system were (Fig. 4):

- anchor with installed accelerometers,

- armored cable inside a pulling tube,

- protective thick pipe around the pulling tube, 


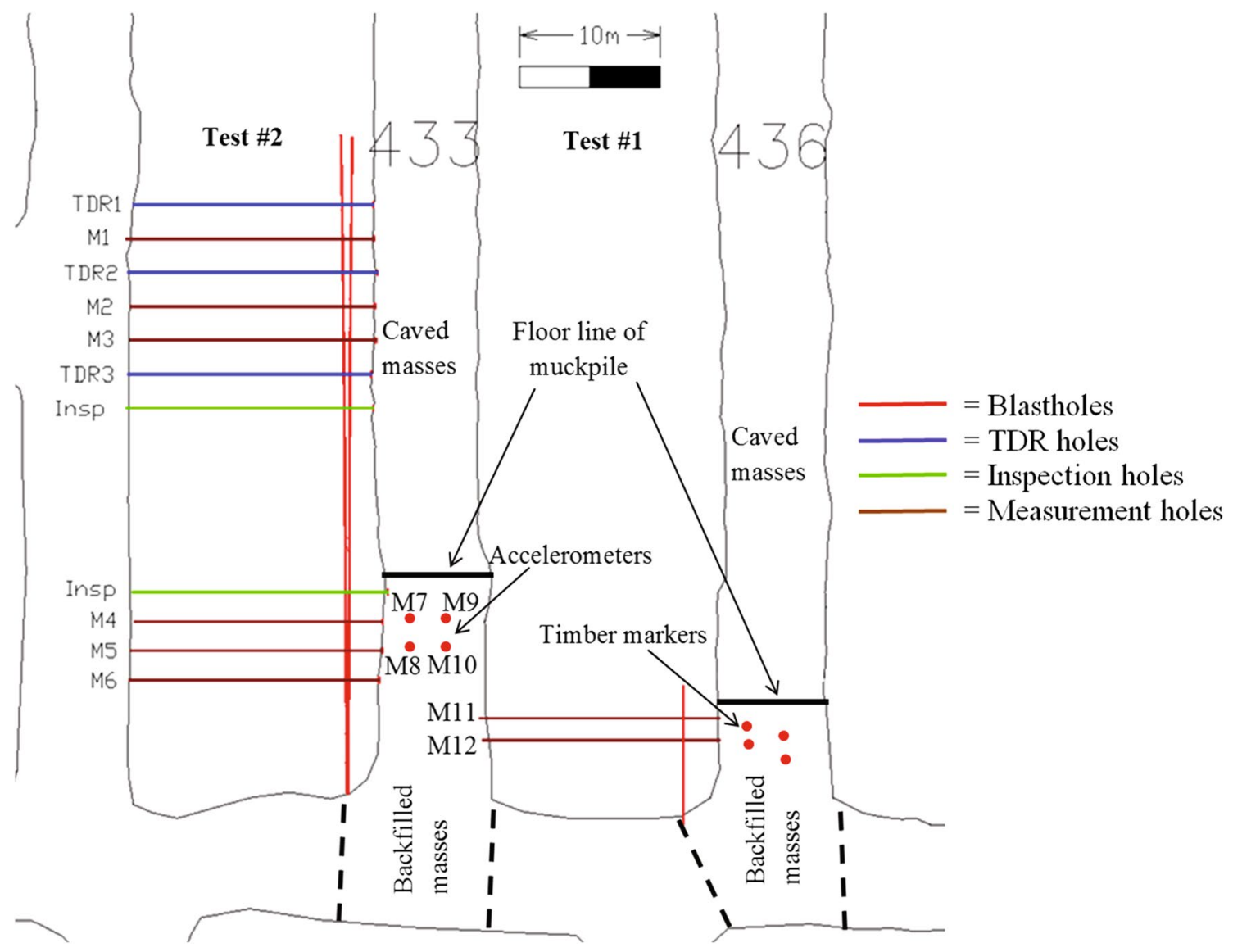

Fig. 3 Two pillars setup (plan view)

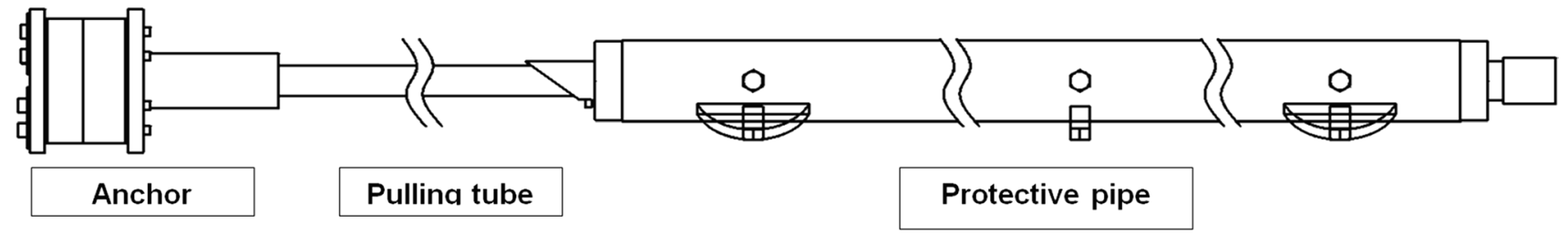

Fig. 4 Measurement system

- expandable spiral cable connected to logging cable (not visible in the figure),

- potentiometric displacement sensor inside the protective pipe (not visible in the figure),

- signal conditioners and data acquisition system (DAS) outside of the measurement holes (not visible in the figure).

The pulling tube is connected to the anchor and provides additional protection to the armored cable. The anchor was installed close to the face of the burden. The length of the system was $4.2 \mathrm{~m}$. The protective pipe was placed in between the blastholes to prevent any damage to the pulling tube and the armored cable.

In test \#1, the measurement systems were equipped with one piezoresistive uniaxial DC accelerometer from Measurement Specialties (Model 3038), one piezoelectric triaxial accelerometer (Model 834M1) from Measurement Specialties and one piezoelectric accelerometer from Endevco (Model 2255B-01). Addition to these sensors, a custommade potentiometric sensor for displacement measurements was installed in the protective pipe.

In test \#2, in 8 out of 10 systems, the sensors installed in the anchor were two accelerometers: one piezoelectric 
uniaxial from PCB Piezotronics (Model 350B-03) and one piezoelectric triaxial from Measurement Specialties (Model 834M1). In the other 2 systems, two accelerometers were installed, one piezoelectric accelerometer from Endevco (Model 2255B-01) and one piezoelectric triaxial from Measurement Specialties (Model 834M1). All the systems had the custom-made potentiometric displacement sensor. All the sensors were connected to a signal conditioner and a DAS located at the neighboring drift (Fig. 2) of the pillars. Each system had its own conditioner and logging unit; the reason for it was to have independence of the systems in case of malfunctioning or fail to trigger.

In test \#2, the instrumentation in the backfilled material was only the anchor of the measurement system which was attached to a steel plate. The anchor contained two accelerometers, i.e., one piezoelectric uniaxial from PCB Piezotronics (Model 350B-03) and one piezoelectric triaxial from Measurement Specialties (Model 834M1), and connected with the armored cable to the logging unit. In this instrumentation, there was no pulling tube or protective pipe.

It was necessary to develop new techniques for the installation of the measurement system as well as the simultaneous initiation of the explosives at both blastholes. The measurement system was designed to slide into a measurement hole. Sliders (steel half-disk shaped elements) were welded on the protective pipe (Fig. 4), and a conical shaped plastic cover was thermally attached to the anchor. The measurement system was pushed toward the burden by attaching pipes to it from the rear side of the measurement hole (Fig. 2).

Two grouting methods were evaluated: (1) attach the grouting hose on the measurement system and push them together into the hole and retracting the hose during grouting and (2) attach the grouting hose at the collar of the hole (rear side) and install a breathing pipe on the measurement system. The first technique was used in test \#1 and the second in test \#2. An expandable grout was developed to enable firm anchoring of the measurement systems. This recipe contained cement, water, and aluminum powder to compensate for the shrinkage of the grout. After laboratory tests, the amount of aluminum powder was defined to be $0.2 \mathrm{wt} \%$ and the optimum water/cement ratio was 0.5 . Additionally, the curing temperature was studied in the laboratory tests. The maximum curing temperature was monitored for $24 \mathrm{~h}$ and reached approximately $40{ }^{\circ} \mathrm{C}$ in room temperature. The peak temperature was reached after $8 \mathrm{~h}$ from grouting. Then, the grout progressively cooled down to $29^{\circ} \mathrm{C}$ after $24 \mathrm{~h}$. A very high temperature influences the sensitivity of the sensors.

The same grouting recipe was also used as stemming material. The usage of this recipe for stemming required some precaution measures as shown in Fig. 5. A separation between the explosives and grout was required (plastic plugs), and the access to the explosive column had to be ensured. Then, a mold was created with two PVC lids to cast the stemming.

Different approaches were tested for the simultaneous initiation of the explosives in the blastholes. There were two reasons for simultaneous initiation (1) to amplify the effect of compaction of the backfilled and caved material and (2) to simulate the middle holes in an SLC production ring which do not have any delay time. The intention was to force the burden to move as one slab toward the backfilled and caved material. The used explosive was a bulk emulsion (Kimulux KR0500 repumpable with $4 \%$ aluminum produced by Kimit $\mathrm{AB})$ in both pillar tests. The velocity of detonation (VoD) of the used explosive was measured prior to the pillar tests, and it was $5560 \mathrm{~m} / \mathrm{s}$ in a $\varnothing 110$ PVC pipe. To achieve parallel propagation of the detonation fronts, detonating cords within the explosive column were used. Several tests were carried out to evaluate the method. The VoD with this configuration was $7563 \pm 25 \mathrm{~m} / \mathrm{s}$. The final setup was composed of a twisted pair of detonating cords $(20 \mathrm{~g} / \mathrm{m})$ along each blasthole which were prepared with precisely measured lengths. After installation in the blastholes, the surplus length was measured and a primer (KP primer), including an electric detonator, was placed so that both columns would initiate
Fig. 5 Stemming plug (section view)

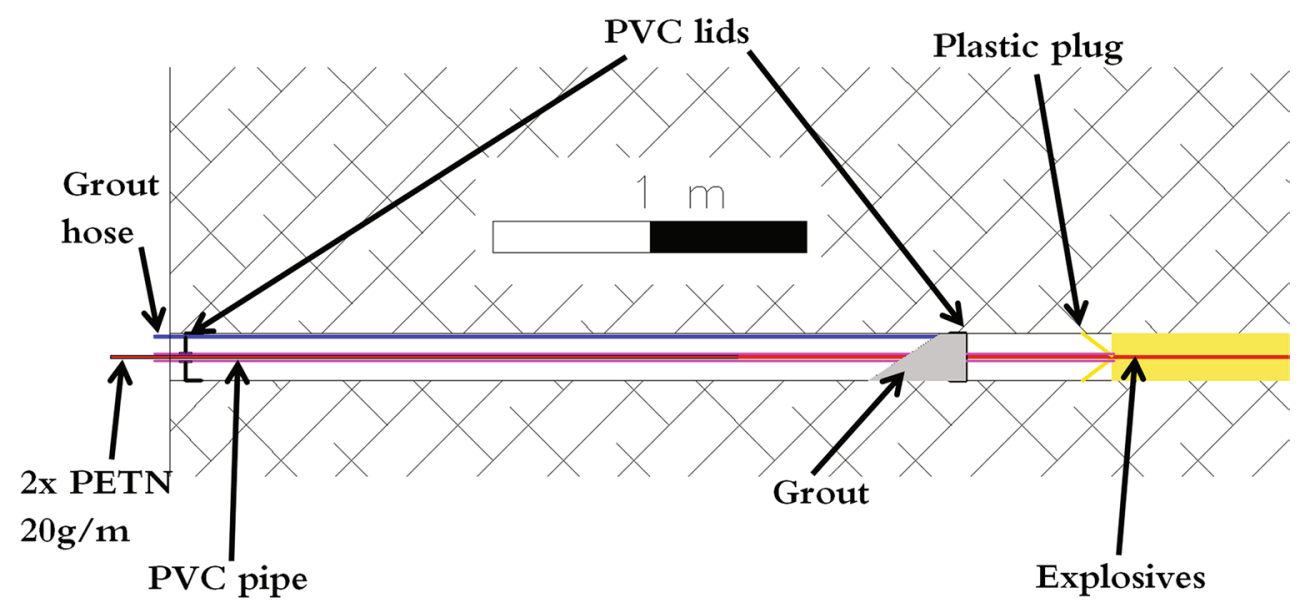


simultaneously. Two electric detonators of $100 \mathrm{~ms}$ were also installed in the blastholes as a redundant measure, in case of a misfire of the main detonator.

\section{Results}

The two pillars were blasted in two different campaigns. The installation techniques gave good results since the measurement systems were installed at the pre-defined locations, and they were firmly grouted. However, the higher pressure in the grout, i.e., the filling method in test \#2, pushed moisture into some of the measurement systems causing short circuit of the sensors. Besides from these problems, the grout recipe performed as designed for all the measurement systems and stemming material. After the blast, the stemming material was still well bonded to the rock on the half-casts of the blastholes.

\subsection{Test \# 1}

The maximum displacement of the burden in test \#1 was $0.98 \mathrm{~m}$ (Fig. 6). This result was a direct measurement from one potentiometric displacement sensor in the measurement system (M11) installed in the burden. The maximum displacement of the burden was not the final displacement due to elastic rebound of the confining material. The final displacement of the burden was approximately $0.8 \mathrm{~m}$, i.e., the size of the gap between the intact rock and the burden. The calculated maximum velocity of the burden from the displacement curve (red line in Fig. 6) was 17-18 m/s. System M12 failed to trigger on time.

The results presented in Fig. 7 were from the burden movement and the timber markers displacement measurements. A calculation of the compaction, volumetric change,

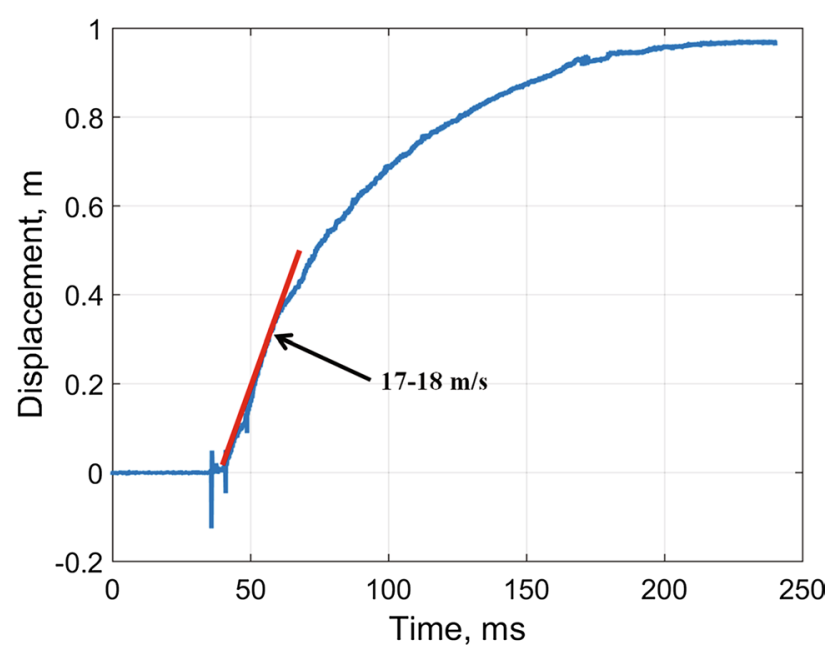

Fig. 6 Test \#1 burden movement

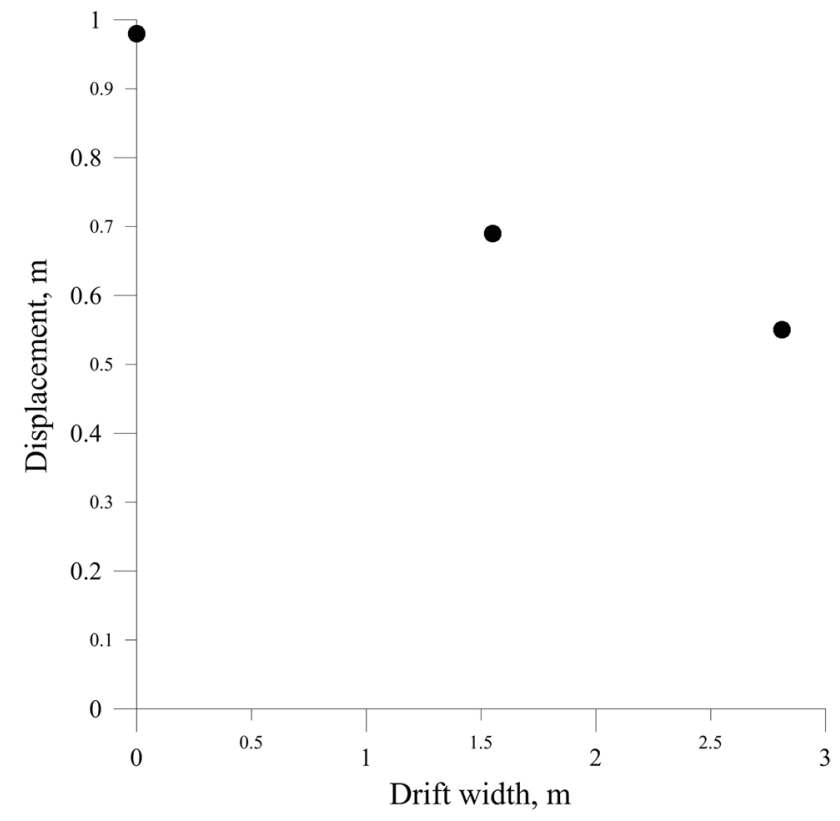

Fig. 7 Displacement results from test \#1

could not be done since the markers were not aligned in one plane with the measurement holes (M11 and M12) after the blast. This was the main reason for replacing the timber markers in test \#2 with the anchor containing accelerometers.

An analysis of the gap between the blasted burden (red color) and the new face of the pillar (blue color) was carried out (Fig. 8). The burden was sliced perpendicular to the blastholes every $1 \mathrm{~m}$ after the stemming part of the blasthole to study the shape of the gap after the blast as shown in Fig. 8. The length at the top of the figure denotes the length of the explosive column. At the beginning of the charged columns, the new face was relatively flat. After approximately $5 \mathrm{~m}$, an apex appeared on the wall and became more intense toward the bottom of the blastholes. The face of the burden was relatively flat (black colored in Fig. 8). The gap was partially filled with burden erosion material, i.e., fine fragmented material from the vicinity of the blastholes and the rear side of the burden.

After the blast, the angle of repose of the backfilled material in test \#1 was measured. The angle was measured at 3 different slopes during mucking. The 1st, 2 nd and 3rd slope angles were $48.3^{\circ}, 46.7^{\circ}$ and $48.8^{\circ}$, respectively. The order of the angles is from the entrance of drift 436 toward the caved material. In situ observations showed that during mucking the material formed locally very steep angles and even negative angles, i.e., the material could support itself, especially in the region close to the burden. The angle of repose before the blast was $33^{\circ}$. This indicates that the frictional forces between the particles increased due to compaction by blasting, but the material structure was very unstable 


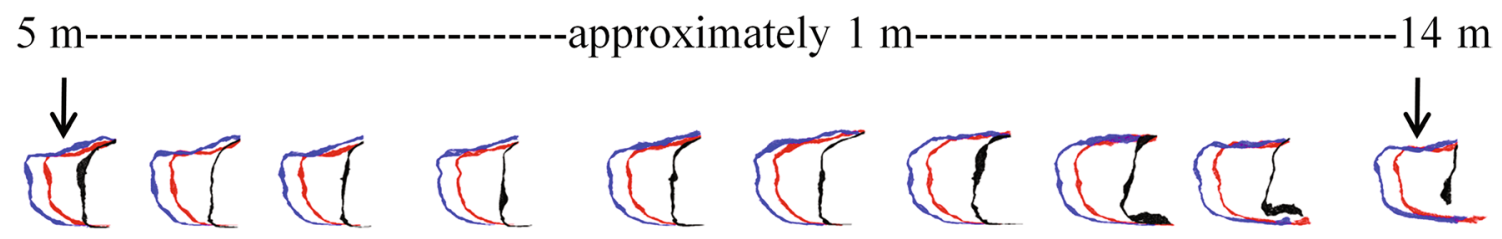

Fig. 8 Gap between new face and blasted burden for test \#1 (red denotes the blasted burden, blue is the new face, and black is the face of the burden)

and sensitive. Even vibrations caused by the loader disturbed the material structure causing the collapse of the backfilled material.

\subsection{Test \#2}

Figure 9 shows an example of the recordings from test \#2. This example is from M8 which was installed in the confining material $2.4 \mathrm{~m}$ from the burden. The upper graph in the figure shows the acceleration measurements, and the two graphs below show the calculated velocity and the displacement of the system. The calculated displacement was $0.42 \mathrm{~m}$. The displacement based on the total station measurement was $0.48 \mathrm{~m}$. The difference between the calculated displacement and the total station result is due to the characteristics of the sensor. Figure 10 shows the displacement results from the systems in the burden and the backfilled material.
The calculated compaction was derived from the displacement data and was 15 and $9 \%$, respectively, for the two profiles along M4-M9 and M5-M10 (Fig. 11). The calculated compaction does, however, not show similar behavior, i.e., decreasing in magnitude as the distance from the burden increases, as the displacement results in Fig. 10. It can be explained by the fact that the drift was not $100 \%$ backfilled due to roof irregularities. Any attempt to fill up the void with a loader could pre-compact the material. Hence, the compacted material was forced to fill the void between the backfilled material and the roof of the drift during blasting. This condition might have significantly affected the calculated compacted area since, in the calculations, it was assumed that the area was fully filled with the backfilled material. The overall compaction of the confining material was calculated based only on the burden displacement and shows the volumetric change in the drift. Thus, the overall compaction of the backfilled material in the drift cross sections was 10 and
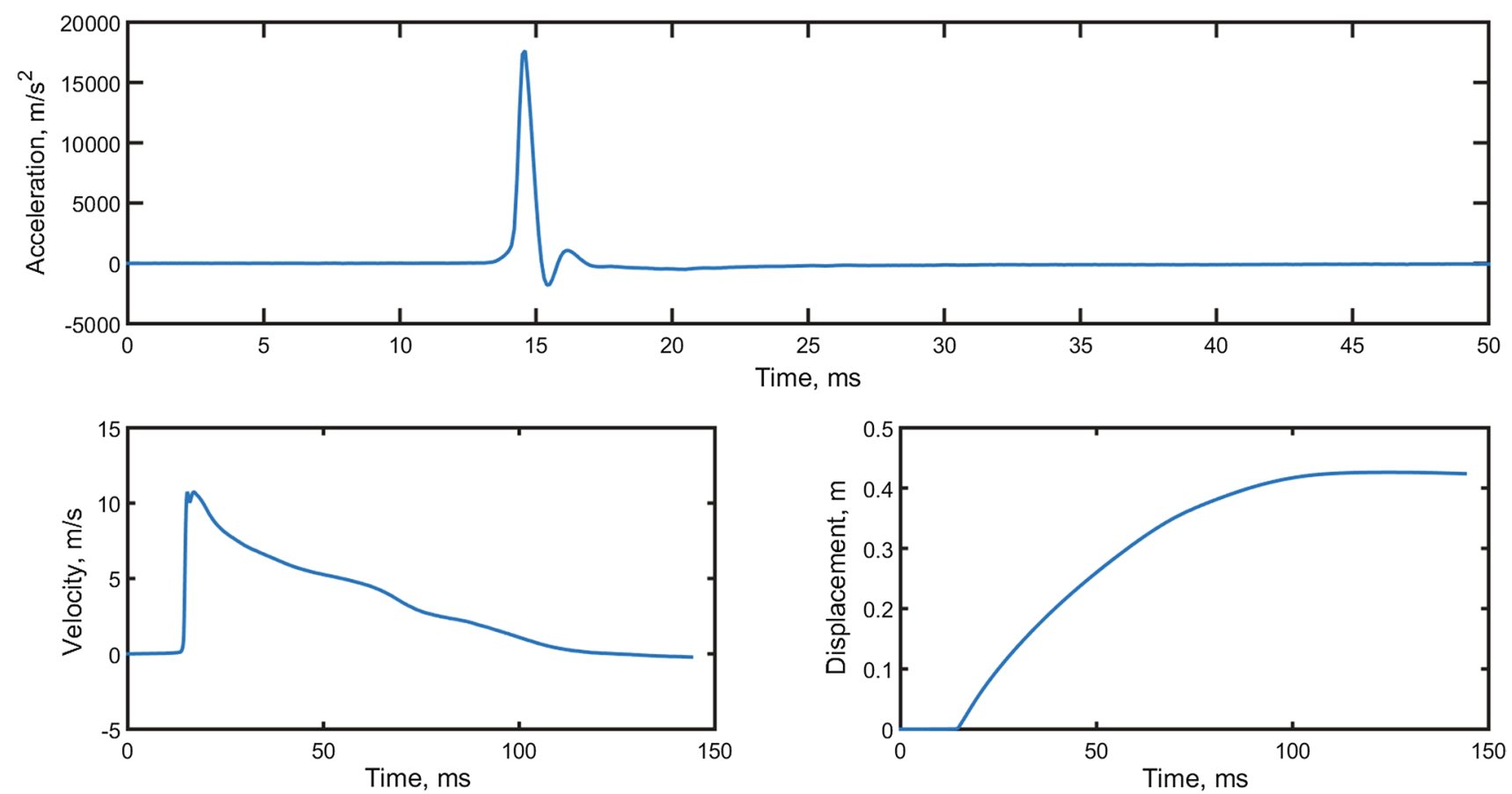

Fig. 9 Results from M8 in the backfilled material 


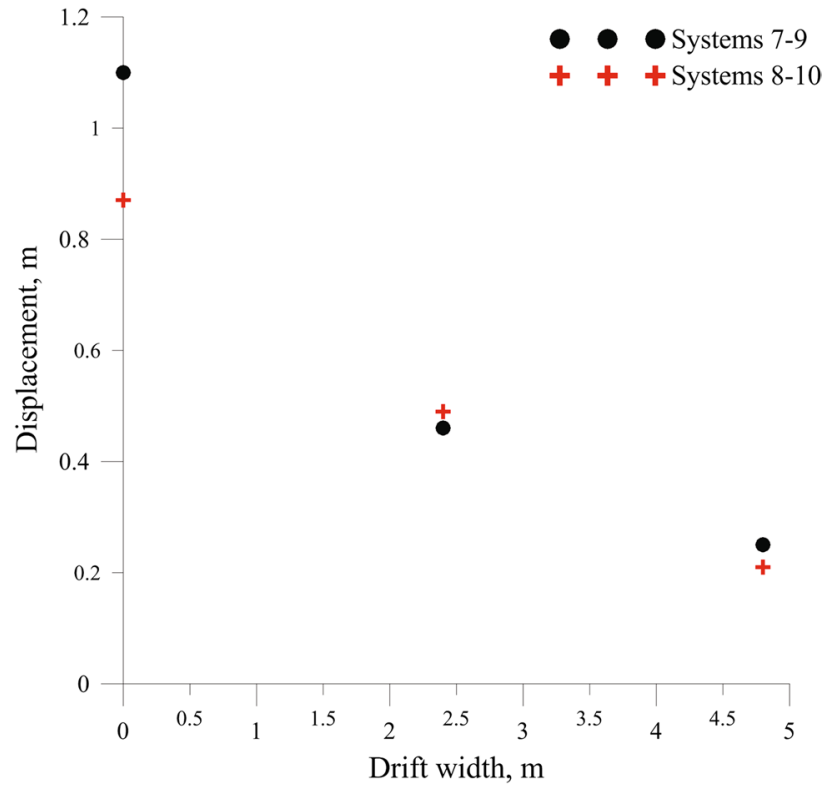

Fig. 10 Displacement results from test \#2

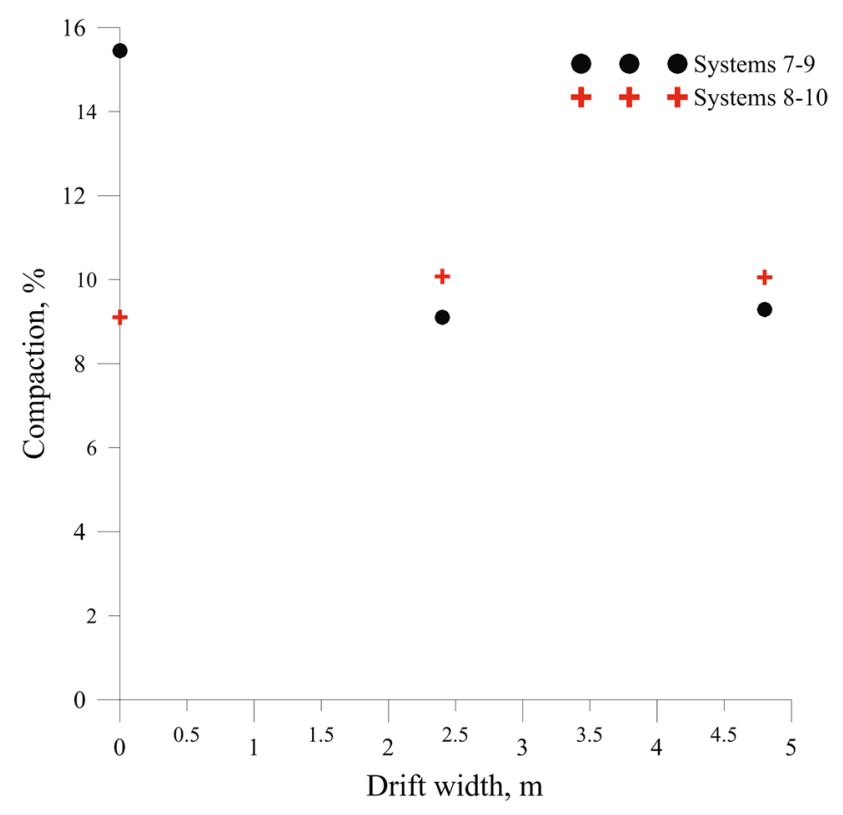

Fig. 11 Calculated compaction for test \#2
9\% for the section systems M4-M9 and M5-M10 (Fig. 3), respectively.

The results from the 3D laser scanner in test \#2 showed that the gap between the blasted burden and the new face in the region of the caved masses became approximately $0.6 \mathrm{~m}$. Therefore, the overall compaction of the caved material was $5 \%$, and the same cross-sectional area as the backfilled drift was assumed for the calculations. Thus, this result can only be used as an indication that the caved material behaved differently than the backfilled material. This different behavior can be explained by the fact that the caved masses were naturally compacted by the material column above; hence, the resistance to compaction was higher than that of the backfilled material.

Based on the burden displacement measurements, the swelling can be calculated. The burden at the two planes, i.e., M4-M9 and systems M5-M10, resulted in a swelling of approximately 31 and $26 \%$, respectively, and at the caved mass region of the pillar, the burden swelling was $23 \%$.

The data from the stereoscopic imaging technique showed the shape of the gap between the intact rock and the blasted material (Fig. 12). The length of the analysis was restricted to $14 \mathrm{~m}$ from the collar due to limited access by the caved masses. The size of the gap varied from 0.9 to $1.1 \mathrm{~m}$ in the area with the backfilled material. However, the gap in the caved material was smaller. In situ measurements and the 3D-laser scan data showed a maximum value of $0.6 \mathrm{~m}$ at the interference zone, i.e., the transition from the backfilled material to the caved masses. Moreover, the size of the gap seemed to get smaller deeper into the area filled with caved masses since it had a conical shape according to 3D-laser scan data. The gap was partially filled with burden erosion material which was finer than the blasted material. An apex appeared in between the blastholes as a result of the simultaneous initiation of the explosives.

The angle of repose of the backfilled material before the blast was $29^{\circ}$. The angle of repose after the blast was measured at 4 different slopes, i.e., $43^{\circ}, 63^{\circ}, 73^{\circ}$ and $66^{\circ}$, from the entrance of drift 433 toward the caved masses. The large difference between the first slope and the rest was due to its location; it was close to the stemming part of the blastholes.

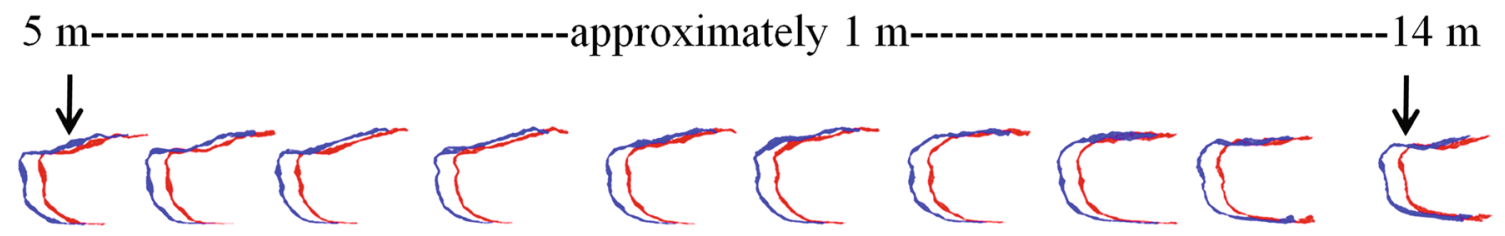

Fig. 12 Gap between new face and blasted burden for test \#2 (red denotes the blasted burden, blue is the new face, and black is the face of the burden) 

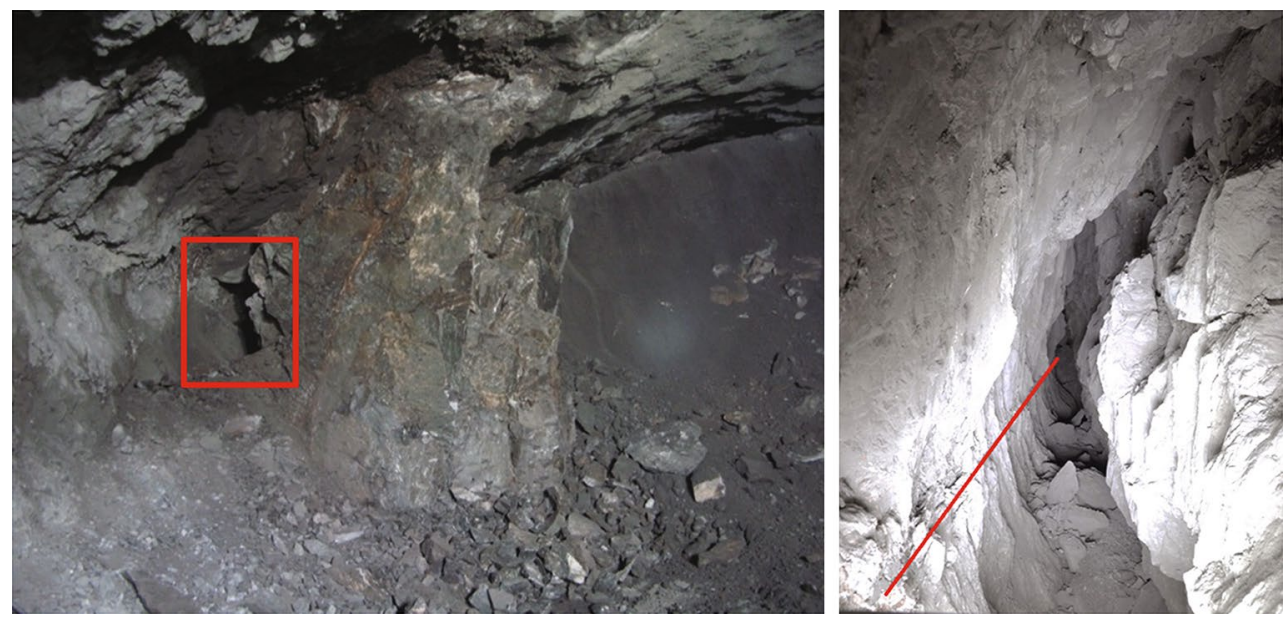

Fig. 13 Burden after blast

The burden moved as one slab due to simultaneous initiation (Fig. 13 left image), as expected. The burden was seemingly broken into fragments with dimensions close to burden dimensions, i.e., $2 \mathrm{~m}$. However, a fracture network was developed during blasting and particles fell apart with significantly smaller dimensions during loading. Based on this burden movement, it is believed that maximum compaction of the backfilled material was achieved. In Fig. 13, the box in the left image shows the location of the right image, which shows the gap and the burden erosion material behind the blasted burden. The red line in the right image denotes the upper blasthole of the pillar. Visual observations in both tests showed that there was no mixing between the blasted material and the backfilled material as proposed by Kvapil (2004) for production SLC rings.

\subsection{Fitting Model to Displacement Results}

The displacement data from the timber markers (test \#1), the instrumentation (test \#2) in the backfilled material as well as the burden movement from the two pillar tests were analyzed, and a simple form of an inverse exponential function was fitted. The selection of the fitting equation was based on the literature, for example, Belen'kii et al. (1969), Barker and Mehta (1993). Figure 14 shows the fit of Eq. (1):

$y=e^{a+b x}$

where $y$ is the displacement of the sensors in the burden and in the backfilled material, $x$ is the distance from the burden face, and $a$ and $b$ are two empirical coefficients. The fitting results seem to give good approximation with the data according to the coefficient of determination $\left(R^{2}\right)$ (Table 2 and Fig. 14).

The dashed lines show the extrapolation of the displacement values to the up to $10 \mathrm{~m}$ distance from the face of the burden ( 5 times the burden for test \#2). As can be seen in Fig. 14, in test \#1, the fitting model shows larger displacement for a longer distance than that of the results from test \#2. The difference between the backfilled materials in the two tests was the size distribution. Hence, the coarser material (test \#1) shows a larger disturbance zone than the finer material (test \#2). The initial value (a) seems to be dependent on the burden behavior since it depends on the burden displacement. The slope coefficient $(b)$ seems to be dependent on the confining material characteristics since there is a tendency of overlapping the two lines from test $\# 2$.

\section{Discussion}

The behavior of the burden and the backfilled material was observed during blasting in the pillar tests. In test \#1, the backfill was a blend of ore and waste from drifting with unknown properties, e.g., bulk density and size distribution. In test \#2, the properties of the backfill were thoroughly studied in the laboratory, in terms of compaction, moisture, size distribution and density (Petropoulos et al. 2017). The angle of repose of the different materials used as backfill was measured pre- and post-blast. It was measured during the mucking process along the axis of the backfilled drift. In test \#1, the backfilled material was coarser than in test \#2, but the angles of repose were similar before the blast. After the blast, the variation in the angle of repose for the two materials was distinguishable. This can be explained by the fact that there was a difference in size distribution since the finer material showed steeper angle of repose than the coarser material. Additionally, the finer material has a larger specific area for each particle; therefore, the friction coefficient is larger than that of the coarser material when compacted. Moreover, the backfilled material in test \#2 


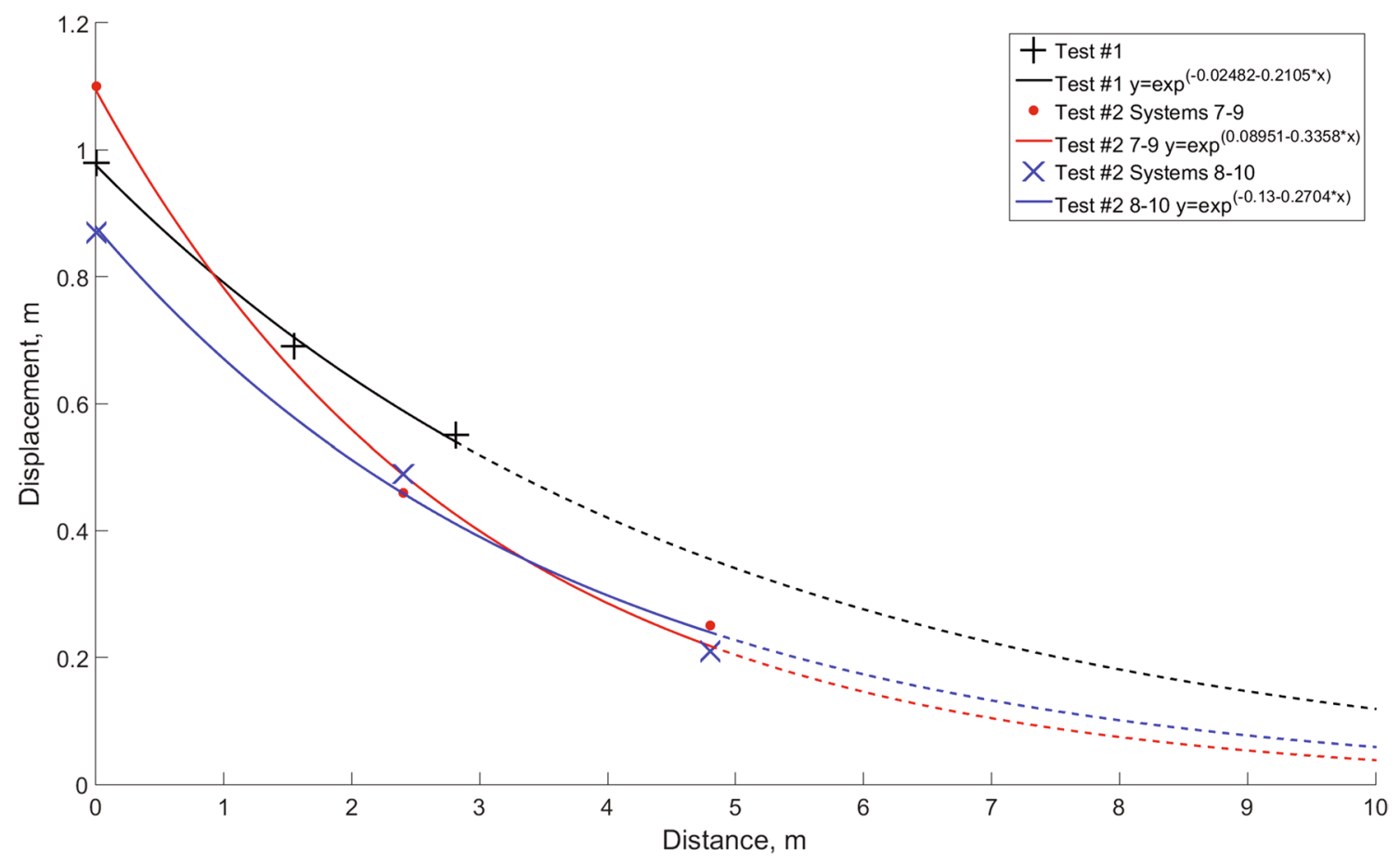

Fig. 14 Displacement results of burden and instrumentation inside the backfilled material

Table 2 Empirical coefficients fit

\begin{tabular}{lcll}
\hline & $a$ & $b$ & $R^{2}$ \\
\hline Test \#1 & -0.02482 & -0.2105 & 0.9967 \\
Test \#2 systems 7-9 & 0.08951 & -0.3358 & 0.9952 \\
Test \#2 systems 8-10 & -0.13 & -0.2704 & 0.9912 \\
\hline
\end{tabular}

was in a pendular state which introduced tensile strength in between the particles promoting agglomeration. In other words, the compacted material exhibited apparent cohesion. It was visually verified during the mucking process that the backfilled material in test \#2 formed vertical walls at the vicinity of the burden and the material structure was not as sensitive as in test \#1.

The volumetric change in the backfilled material is too complex to be accurately calculated due to the irregularities of the wall of the backfilled drift. An overall estimation of the compaction can be made in the two pillar tests where the backfilled material showed larger compaction than the caved mass, i.e., approximately 9-10\% for the backfilled and $5 \%$ for the caved mass part. Similar compaction results have been observed by Wimmer (2012) where the backfilled material was coarser than that in test \#2 and similar as in test \#1. The difference in the values can be explained by the different boundary conditions that apply in each case. The backfilled material had different packing density than that of the caved masses.
Additionally, the filling percentage of the drift was not $100 \%$ due to roof irregularities. Another large difference between the backfilled material and the caved material was the confinement. The backfilled material was placed in a drift, i.e., confined by the wall/roof of the drift; on the other hand, the caved material was not confined since it was a result of a production SLC blast, i.e., there is no roof to confine the caved material.

Based on these tests, it was concluded that it is better to measure the displacement of an object placed in a backfilled material than to calculate the compaction since it is a volumetric quantity, and the volume is not defined in the latter case. The burden displacement can be used to calculate swelling, the burden moved as one slab creating a gap between the blasted material and the new face. The calculated values are in the range observed by other researchers, for example, Wimmer and Ouchterlony (2011), although the values are larger than Newman et al. (2008), i.e., 2-17\%.

The datasets from the instrumentation in the burden and the backfilled material were approximated with an inverse exponential function which gave good fitting results for both pillar tests. The coarser backfilled material in test \#1 shows a larger disturbance zone (compaction zone) than the finer backfilled material in test \#2. Consequently, the size distribution of the confining material affects the size of the disturbance zone. Also, the reaction of the confining material during blasting seems to be dependent on the content of water which is related to the angle of repose. 
During blasting, a gap was formed between the blasted material and the new face of the pillar, and the material in this gap, i.e., the burden erosion material, was finer than to the blasted material. The size of the gap depends on the packing degree of the confining material as observed in test \#2, where it was reduced from approximately $1 \mathrm{~m}$ in the backfilled material to $0.6 \mathrm{~m}$ in the caved masses region.

It was observed that the burden in confined conditions moves backward after reaching its maximum displacement (Petropoulos et al. 2013). The backward displacement depends on the characteristics of the backfilled material such as the type of material, size distribution and compressibility. As the burden moves backward due to the recovery of the elastic compression of the confining material after the blast, the burden compresses the burden erosion material. This results in three materials, i.e., the burden erosion material, the blasted burden and the confining material, with different characteristics such as bulk density, compressibility and mobility, which are compacted with different compression rates. The different rates might result in different compaction states of the burden erosion material as well as for the blasted material.

Considering a production SLC ring, if the burden erosion material and the blasted material are over-compacted and there is water in the rock mass, the materials might show apparent cohesion and bond with the new face of the intact rock. This condition can disturb the flow of the blasted material by creating arches. This might be the starting point of an arch formation between the intact rock and the burden erosion material. For the endpoint of the arch (contact between burden and confining material), an over-compaction material state is also required to create abutment for supporting the arch. This state was observed in test \#2 in the vicinity of the burden, i.e., up to $1 \mathrm{~m}$ distance from the face of the burden. At this stage, the confining material was agglomerated and bonded on the face of the burden.

The above-mentioned observations can be correlated with a special case in production SLC rings where the above conditions are met and resulted in the formation of an arch which can temporarily or permanently halt the flow of the blasted material. Similar observations have been made in production SLC rings in different underground mines based on studies on hang-ups (Wimmer 2012; Power 2003). The apparent cohesion might be the trigger mechanism to start the formation of an arch, and then, particle interlocking might improve the stability of the arch. This special case can be related to the "shallow draw phenomenon" as has been observed by Power (2003), Selldén and Pierce (2004) and Wimmer (2012) where over-compacted material was observed.

\section{Conclusions}

The results from the pillar tests showed the behavior of the blasted material in confined conditions as well as the behavior of the confining materials. The tests have led to the following conclusions:

- The finer confining material showed steeper angle of repose after the blast which indicates higher friction coefficient than the coarser confining material.

- The confining material in test \#2 was over-compacted and in combination with the water exhibited apparent cohesion which was limited in the confining material in test \#1. The appearance of apparent cohesion might be the trigger mechanism for disturbances in the flow of the blasted material in production SLC rings.

- The compaction zone in the backfilled material follows an inverse exponential function. The disturbance zone is larger for the coarser confining material. The two empirical coefficients seem to be dependent on the burden movement (initial value, $\alpha$ ) and the confining material characteristics (slope coefficient, $b$ ).

- A gap was observed between the blasted material and the new face, and it was partially filled with burden erosion material. This material might have an effect to the flowability of the blasted material in the SLC production rings.

Acknowledgements The authors thank the Hjalmar Lundbohm Research Centre (HLRC), a research foundation at Luleå University of Technology, endowed by LKAB for its financial support of the titled project "Improved understanding of sublevel blasting: Determination of the extent of the compacted zone, its properties and the effects on caving." Swebrec and LKAB are also thanked for partially financing this project. Drilling, charging and mucking were an in-kind financial contribution by LKAB. Additionally, Dimitar Mihaylov (LTU), Anders Nordqvist (LKAB) and LKAB technicians Jonny Olofsson and Johanna Johansson are thanked for their assistance during the preparation of the pillar tests. In addition, Mikael Svartsjaern (LTU) is thanked for constructive discussions.

Open Access This article is distributed under the terms of the Creative Commons Attribution 4.0 International License (http://creativeco mmons.org/licenses/by/4.0/), which permits unrestricted use, distribution, and reproduction in any medium, provided you give appropriate credit to the original author(s) and the source, provide a link to the Creative Commons license, and indicate if changes were made.

\section{References}

3GSM (2010) ShapeMetriX3D, version 3.5, user manual, 3GSM $\mathrm{GmbH}$, Graz 
ASTM D2487-11 (2011) Standard practice for classification of soils for engineering purposes (Unified soil classification system). American Society for Testing and Material, West Conshohocken

Barker GC, Mehta A (1993) Transient phenomena, self-diffusion and orientational effects in vibrated powders. Phys Rev 47(1):184-188

Belen'kii EV, Kovtun IN, Fedorenko PI (1969) Buffer properties of caved ore. Sov Min Sci 5(4):444-447

Bull G, Page C (2000) Sublevel caving-today's dependable low cost "ore factory". In: Chitombo G (ed) 3rd International conference and exhibition on mass mining. The Australasian Institute of Mining and Metallurgy, Melbourne, Australia, pp 537-556

Johansson D (2011) Effects of confinement and initiation delay on fragmentation and waste rock compaction. Results from smallscale tests. Ph.D. thesis, Lulea University of Technology, Lulea

Kvapil R (2004) Gravity flow in sublevel and panel caving-a common sense approach. Supplement book to MassMin 2008, Lulea

Newman T (1996) Blasting of intact ore against caved waste rock at Kiruna. LKAB internal report, Kiruna

Newman T, Hustrulid W, Quinteiro C (2008) Sublevel caving trialmonitoring effects from blasting an ore slice against caved rock at LKAB's Kiruna mine, Sweden. In: Schunnesson H, Norldund E (eds) 5th International conference and exhibition on mass mining. Luleå University of Technology, Luleå, pp 705-713

Petropoulos N, Johansson D, Ouchterlony F (2013) Fragmentation under different confinement conditions and the burden behaviorsmall scale tests. In: Sanchidrian J, Singh AK (eds) Measurement and analysis of blast fragmentation: workshop hosted by FRAGBLAST 10 - 10th international symposium on rock fragmentation by blasting. CRC Press, New Delhi, pp 61-70

Petropoulos N, Mihaylov D, Johansson D, Wimmer M, Nordqvist A (2015) Design of equipment for dynamic burden measurements. In: Spathis AT, Gribble DP, Torrance AC, Little TN (eds) 11th International symposium on rock fragmentation by blasting. The
Australasian Institute of Mining and Metallurgy, Melbourne, Australia, pp 493-500

Petropoulos N, Johansson D, Nordlund E (2017) Crushed aggregate response upon impact in dry and wet conditions. J Earth Sci Geotech Eng 7(3): 1-22

Power G (2003) Modelling granular material flow in caving mines: large scale physical modelling and full scale experiments. Ph.D. thesis, University of Queensland, Brisbane

Rustan A (1970) Theoretical basics of the volume-weight-method for the determination of the ore content of a mixture of blasted ore and waste rock. Kinematics, swelling, loosening and fragment size in the burden for confined blasting in model-scale. Licentiate thesis, Royal Institute of Technology, Stockholm (in Swedish)

Rustan A (2013) The dynamics and fragmentation of blasted ore slices in scaled sublevel caving and slab models followed by accuracy analysis of the "Volume weight method" used for determination of ore content at loading. In: Singh P, Sinha A (eds) FRAGBLAST 10 -10th international symposium on rock fragmentation by blasting. CRC Press, New Delhi, pp 357-371

Selldén H, Pierce M (2004) PFC3D modeling of low behavior in sublevel caving. In: Karzulovic A, Alafaro MA (eds) 4th International conference and exhibition on mass mining. Instituto de Ingenieros de Chile, Santiago, Chile, pp 201-214

Volchenko NG (1977) Influence of charge arrangement geometry and short-delay blasting on the crushing indices in compression blasting. Sov Min Sci 13(5):488-493

Wimmer M (2012) Towards understanding breakage and flow in sublevel caving (SLC) - development of new measurement techniques and results from full-scale tests. Ph.D. thesis, Luleå University of Technology, Luleå

Wimmer M, Ouchterlony F (2011) Study of burden movement in confined drift wall blasting tests at block 12, $691 \mathrm{~m}$ level, Kiruna. Swebrec report, Kiruna 